\title{
The influence of maturational and morphological status pre- and post-menarche on the 100-m freestyle swimming performance of competitive teenagers
}

\author{
Beatriz Matias Avelino do Bonfim ${ }^{1}$ (D) , Giordano Marcio Gatinho Bonuzzi² (D) , Vitoria Leite Domingues ${ }^{3}$ (D) , \\ Fernando Carvalheiro Reiser ${ }^{1}$ \\ ${ }^{1}$ Universidade de São Paulo, Escola de Artes Ciências e Humanidades, Laboratório de Ciências na Atividade Física, \\ São Paulo, SP, Brasil; ${ }^{2}$ Universidade Estadual do Piaui, Departamento de Educação Física, Picos, PI, Brasil; ${ }^{3}$ Universidade \\ de São Paulo, Escola de Educação Física e Esportes, Laboratório de Comportamento Motor, São Paulo, SP, Brasil. \\ Associate Editor: Dustin Jay OranchuK, Auckland University of Technology, New Zealand.
}

\begin{abstract}
Aim: This study investigated whether the difference anthropometric of swimmers pre- and post-menarche influence the motor performance of a 100-m freestyle swimming test. Methods: Twenty-five female swimmers participated in this study, nine swimmers have not had menarche (age 11.7 \pm 0.63 ), and sixteen swimmers already have had it (age 15.17 \pm 1.36 ). Body composition (skinfold thickness), anthropometrical parameters (height and weight), and biological age (Tanner self-assessment) were measured. A univariate and multivariate linear regression analysis was run to assess which personal or anthropometric variable predicts the motor performance (time trial) on a 100-m freestyle swimming test in pre- and post-menarche participants. As well, it was performed a Pearson's correlation test between the maturational status on Tanner self-assessment and the motor performance. Results: Post-menarche swimmers demonstrated better motor performance than pre-menarche swimmers. Anthropometric characteristics did not predict the motor performance of pre-menarche swimmers. Age, height, and weight predicted $47.8 \%$ of the motor performance of postmenarche swimmers. The Tanner classification demonstrated a strong negative correlation with swimming performance. Conclusion: Anthropometric characteristics only impacted the motor performance of post-menarche swimmers.
\end{abstract}

Keywords: menarche; maturation; swimming; biological development.

\section{Introduction}

The process of biological maturation induces critical morphofunctional transitions across the adolescence period. This process influences the anthropometric characteristics such as height, body fat, and muscle mass, affecting the physical and motor performance ${ }^{1,2}$. In the female athletes, the menarche is a critical marker of the biological maturity, and it occurs due to the increase in the production of sexual hormones associated with the appearance of secondary sexual characteristics ${ }^{1,3,4}$.

Menarche is related to the deceleration of somatic growth and the increase in the percentage of body fat, especially in mamas and hips regions ${ }^{1,4}$. In Brazil, the mean age for menarche occurrence is 12.2 years old ${ }^{3}$; however, its period is fluctuating depending on geographic factors, seasonality, nutritional status, physical activity, racial differences, emotional conditions, pheromonal effect, and physical training ${ }^{1,5,6}$.

Some studies have demonstrated that a lower body fat percentage is a strong predictor of delay in menarche occurrence ${ }^{1}$. In this sense, the high volume of physical training imposed on female teenagers athletes can induce alterations in the body weight and composition, delaying the female sexual maturation process and, consequently, the menarche occurrence ${ }^{7,8}$.

It has been demonstrated that the late menarche occurrence favors athletic performance in teenage athletes and the following competition categories (adults or professional categories) ${ }^{9,10}$. One explanation for that can be attributed to morphological aspects, because 1 - there is a propensity for young women with later menarche to reach a greater height in adulthood, given that the menarche occurs after the somatic growth peak ${ }^{1,11}$; and, 2 Specifically in swimming athletes, a higher height is associates with a better performance ${ }^{12}$. In this way, we aimed to investigate the influence of maturational (menarche occurrence) and morphological status (body fat and height) on the performance in the $100-\mathrm{m}$ freestyle swimming of competitive teenagers.

\section{Materials and Methods}

The Ethics Committee from the School of Arts, Sciences and Humanities of the University of São Paulo, São Paulo SP, Brazil, approved this study; register number 508.147. All participants signed the assent term, and the participant's parents signed the consent term.

\section{Subjects}

The participants were recruited in the training gymnasium were they were engaged in swimming practice. Twenty-five female swimming competitors participated in this study, Age (years): \pm 13.32 , max: 16 , minimum: 10 . As inclusion criteria 
were adopted: 1 - to be affiliated to the Sao Paulo Aquatic Federation, 2 - To participate in swimming competition, 3 - a minimum of 12 hours of swimming training per week.

For exclusion criteria were considered: 1 - Cardiovascular diseases, 2 - Not being able to practice physical activity regarding "Physical Activity Readiness Questionnaire" (PAR-Q), 3-Not sign the informed consent form. 4 - Less than three years of systematic practice of swimming.

\section{Design and procedures}

In an individual interview, each participant was asked about their birth date and whether the participant already has menarche. If yes, it was asked at which age the menarche occurred. Parent's support was allowed in answer to these questions. To avoid embarrassment to the participant, this interview was conducted by a woman researcher.

After, the swimmers were enrolled in an anthropometric assessment that assessed the body weight and height (using a calibrated digital scale with a stadiometer, ${ }^{\circledR}$ Sanny - BL201PP). For the body fat evaluation, the participants were assessed regarding their triceps, abdomen, and thigh skinfold thickness measurements (using a $₫$ Lange Skinfold Caliper Model C-130), according to Lohman, Roache, and Martorell ${ }^{13}$ 's anthropometric standardization reference manual. All anthropometric assessments were performed by a unique Physical Education professional with 5 years of experience in physical assessment.

The Tanner self-assessment ${ }^{14}$ of pubic hair and mama development tests were performed to estimate and characterize the maturational development of the participants. In this test, the maturation levels are stratified from 1 to 5 levels, where level 1 represents the pre-pubertal level (of the mama or pubic hair), and level 5 represents the post-pubertal level, which corresponds to the full maturity (of the mama or pubic hair).

Finally, the participants initiated the performance test. It begins with a warmup composed of 5 minutes of a freestyle swimming in a self-choice graded intensity. Then, the participants were engaged in a 100-m freestyle swimming test. All official rules from the International Swimming Federation - Fédération Internationale de Natation (FINA) was considered for the motor performance test. The performance was computed by the trial time that was acquired manually by the researcher (with experience in teaching swimming) using a chronometer (®SEIKO S141 - 300 Lap Memory). The researcher was blind regarding the participant's characteristics.

\section{Statistical analysis}

The statistical analysis was run in the SPSS v.22 and Microsoft Excel 365 software. The alpha of 5\% was adopted for the significance level in the inferential analysis. The assumptions of normal data distribution were verified using the Kolmogorov-Smirnov and Shapiro-Wilk test, and equality of variances (homoscedasticity), using the Levene test.

For all analyses, the participants were divided into 2 groups:
Pre-menarche group composed of participants that have not had menarche, and Post-menarche group for participants that already had menarche.

To investigate whether the menarche occurrence induces a significant difference on the anthropometric measures and the motor performance in the 100-m freestyle swimming test. The personal characteristic and the motor performance in the 100$\mathrm{m}$ freestyle swimming test were compared in a T-test between the groups.

It was performed a multiple linear regression analysis to examine whether the anthropometric characteristics predict the motor performance in each group. The independent variables that were considered in the multiple linear regression models were determined in a univariate analysis.

Therefore, the independent variables (1 - weight (kilograms), 2 - height (centimeters), 3 - the sum of skinfold thickness measures in a tenth of millimeters (triceps + abdomen + thigh), 4 - Body Mass Index (BMI), 5-Age (days), 6 - Time since menarche (years)) significantly correlated with the motor performance in the 100-m freestyle swimming test (trial time in seconds) in the univariate analysis were considered into a multiple linear regression analysis model with the time trial as the dependent variable by force entry (enter method).

No multi-collinearity in the multiple regression analysis was found by screening a correlation matrix of all included variables $(\mathrm{r}<0.8)$ and by evaluating the variance inflation factors (above 10 ) and tolerance statistics (below 0.10). There was no autocorrelation found with the Durbin-Watson test of independence of residuals. The assumptions of linearity, homoscedasticity, and normally distributed residuals were met when checking the histograms and normal probability plots of the residuals. Outliers were checked by evaluating the percentage of standardized residuals with an absolute value greater than three, and there were no outliers.

As a complementary analysis to infer the relation between the maturational status and the performance in the 100-m freestyle swimming test, it was developed a correlation analysis (Pearson's correlation coefficient) with all participants in a unique group between the results of pubic hair and mama development in the Tanner self-assessment ${ }^{14}$ with the trial time in the swimming test.

\section{Results}

Participant's personal, maturational, anthropometric and motor performance information can be checked in Table 1 . Regarding the menarche occurrence, nine participants have not had menarche, while sixteen participants already have it. The results of the Tanner self-assessment test demonstrated relation to the menarche occurrence, given that the most participants in the stages 1 and 2 for pubic hair and mama development in Tanner self-assessment test have not had menarche. On the other hand, all participants in stages 4 and 5 in Tanner self-assessment already had menarche.

The T-test revealed a significant difference between pre- and post-menarche participants regarding Time Trial, with post-menarche participants demonstrating a better motor performance 
than pre-menarche participants. As well, there was a significant difference between pre- and post-menarche for skinfold thickness, weight, height, and age. For BMI, there was no significant difference between the groups.

Table 2 shows the results of univariate linear regression in the pre-menarche group. No significant result was found in any analyses. Therefore, for the pre-menarche group, we did not run the multiple linear regression. This result demonstrated that the morphological status of the pre-menarche group did not have a relation with motor performance.

Table 3 shows both univariate and multivariate linear regression in the post-menarche group. In the univariate analysis, age, weight, and height demonstrated a significant difference with the time trial as a dependent variable. So, these independent variables (age, weight, and height) were considered into the multivariate linear regression. In this last analysis was demonstrated that younger age, lower body weight, and a higher height could explain $47.8 \%$ of the time trial of the post-menarche participants. However, the independent variables (age, weight, and height) were not significant in the model. This finding revealed that for female teenagers that already have menarche, the interaction among age, weight, and height predicted almost half of the motor performance in the 100-m freestyle swimming test.

Lastly, we identified that the maturational classification derived from pubic hair $(\mathrm{r}=-.81)$ and mama development $(\mathrm{r}=$ -.80) in the Tanner self-assessment test demonstrated a strong negative correlation with motor performance in the $100-\mathrm{m}$ freestyle swimming test (Time Trial) in the Pearson's correlation test, as can be seen in Figure 1. This result indicated the inversely proportional relationship between maturational status level and 100-m freestyle swimming motor performance, where a more matured condition was associated with a lower trial time.

Table 1 - Personal, maturational, morphologic and motor performance of the participants.

\begin{tabular}{|c|c|c|c|c|}
\hline & $\begin{array}{c}\text { Total } \\
\mathrm{n}=\mathbf{2 5}\end{array}$ & $\begin{array}{c}\text { Pre- menarch } \\
\mathbf{n}=9\end{array}$ & $\begin{array}{c}\text { Post- menarch } \\
n=16\end{array}$ & $\begin{array}{c}\text { T-test } \\
\text { (p-value) }\end{array}$ \\
\hline Age (years) & $13.92 \pm 2.05$ & $11.7 \pm 0.63$ & $15.17 \pm 1.36$ & $<0.001^{*}$ \\
\hline Time of menarche (years) & & & $3.11 \pm 1.62$ & \\
\hline \multirow{5}{*}{ Pubic Hair classification Tanner } & Stage $1: \mathrm{n}=0$ & Stage $1: \mathrm{n}=0$ & Stage $1: \mathrm{n}=0$ & \\
\hline & Stage $2: \mathrm{n}=7$ & Stage $2: \mathrm{n}=7$ & Stage $2: \mathrm{n}=0$ & \\
\hline & Stage $3: \mathrm{n}=2$ & Stage $3: \mathrm{n}=1$ & Stage $3: \mathrm{n}=1$ & \\
\hline & Stage $4: \mathrm{n}=9$ & Stage $4: n=1$ & Stage $4: \mathrm{n}=8$ & \\
\hline & Stage $5: \mathrm{n}=7$ & Stage $5: \mathrm{n}=0$ & Stage $5: \mathrm{n}=7$ & \\
\hline \multirow{5}{*}{$\begin{array}{l}\text { Mama development } \\
\text { classification Tanner }\end{array}$} & Stage $1: \mathrm{n}=1$ & Stage $1: \mathrm{n}=1$ & Stage $1: \mathrm{n}=0$ & \\
\hline & Stage $2: \mathrm{n}=6$ & Stage $2: \mathrm{n}=6$ & Stage $2: \mathrm{n}=0$ & \\
\hline & Stage $3: n=6$ & Stage $3: \mathrm{n}=3$ & Stage 3: $n=4$ & \\
\hline & Stage $4: \mathrm{n}=8$ & Stage $4: \mathrm{n}=0$ & Stage $4: \mathrm{n}=8$ & \\
\hline & Stage $5: n=2$ & Stage $5: \mathrm{n}=0$ & Stage $5: \mathrm{n}=2$ & \\
\hline Time Trial (seconds) & $1.123 \pm 0.116$ & $1.254 \pm 0.07$ & $1.049 \pm 0.06$ & $<0.001^{*}$ \\
\hline $\begin{array}{l}\text { Skinfold thickness } \\
\text { triceps }+ \text { abdomen }+ \text { thigh } \\
\text { (tenth of a mm })\end{array}$ & $35 \pm 10$ & $41.33 \pm 12.37$ & $31.44 \pm 6.39$ & $<0.01 *$ \\
\hline Weight (kg) & $51.22 \pm 10.12$ & $43.71 \pm 11.47$ & $55.45 \pm 6.38$ & $<0.01^{*}$ \\
\hline Height (cm) & $158.2 \pm 9.57$ & $149.67 \pm 8.53$ & $163 \pm 6.28$ & $<0.001 *$ \\
\hline BMI $\left(\mathrm{kg} / \mathrm{cm}^{2}\right)$ & $20.44 \pm 2.89$ & $19.31 \pm 3.84$ & $21.08 \pm 2.09$ & $>0.5$ \\
\hline
\end{tabular}

Note: Data are presented as mean \pm standard deviation. T-test compared the personal, maturational, morphologic and motor performance between pre- and postmenarche participants. The information concerning the participant's age is demonstrated in years in the table for better comprehension. However, the T-test was performed with age in days for a more accurate analysis.

Legend: N - number of participants; BMI - Body Mass Index; kg - kilogram; cm - centimeter; mm - millimeter; Tanner - Tanner self-assessment test; * significant difference. 
Table 2 - Univariate linear regression in the pre-menarche group with motor performance (time trial) as a dependent variable.

\begin{tabular}{ccc}
\hline & $\mathbf{R}^{\mathbf{2}}$ & p-value \\
\hline $\begin{array}{c}\text { Skinfold thickness } \\
\text { triceps + abdomen + thigh }\end{array}$ & 0,039 & 0,609 \\
Weight & 0,199 & 0,229 \\
Height & 0,000 & 0,989 \\
BMI & 0,010 & 0,795 \\
Age & 0,056 & 0,539 \\
\hline
\end{tabular}

Legend: BMI - Body mass index.

Table 3 - Univariate and multivariate linear regression in the post-menarche group with the motor performance (time trial) as a dependent variable.

\begin{tabular}{|c|c|c|c|c|c|}
\hline & \multicolumn{3}{|c|}{ Univariate } & \multicolumn{2}{|c|}{ Multivariate $^{\mathrm{a}}$} \\
\hline & $\mathbf{R}^{2}$ & $\beta$ & $\mathbf{p}$ & $\beta$ & $\mathbf{p}$ \\
\hline $\begin{array}{l}\text { Skinfold thickness } \\
\text { triceps }+ \text { abdomen }+ \text { thigh }\end{array}$ & 0,015 & $-0,122$ & 0,653 & & \\
\hline Age & 0,296 & $-0,544$ & $0,029 *$ & $-0,320$ & 0,206 \\
\hline Weight & 0,295 & $-0,543$ & $0,030 *$ & $-0,336$ & 0,210 \\
\hline Height & 0,326 & 0,571 & $0,021 *$ & $-0,207$ & 0,453 \\
\hline BMI & 0,048 & $-0,220$ & 0,413 & & \\
\hline Time of menarch & 0,047 & $-0,217$ & 0,419 & & \\
\hline
\end{tabular}

Legend: BMI - Body mass index; * significant values ; ${ }^{\mathrm{a}}-\mathrm{R}^{2}=0.478$ and $\mathrm{p}=0.044$.

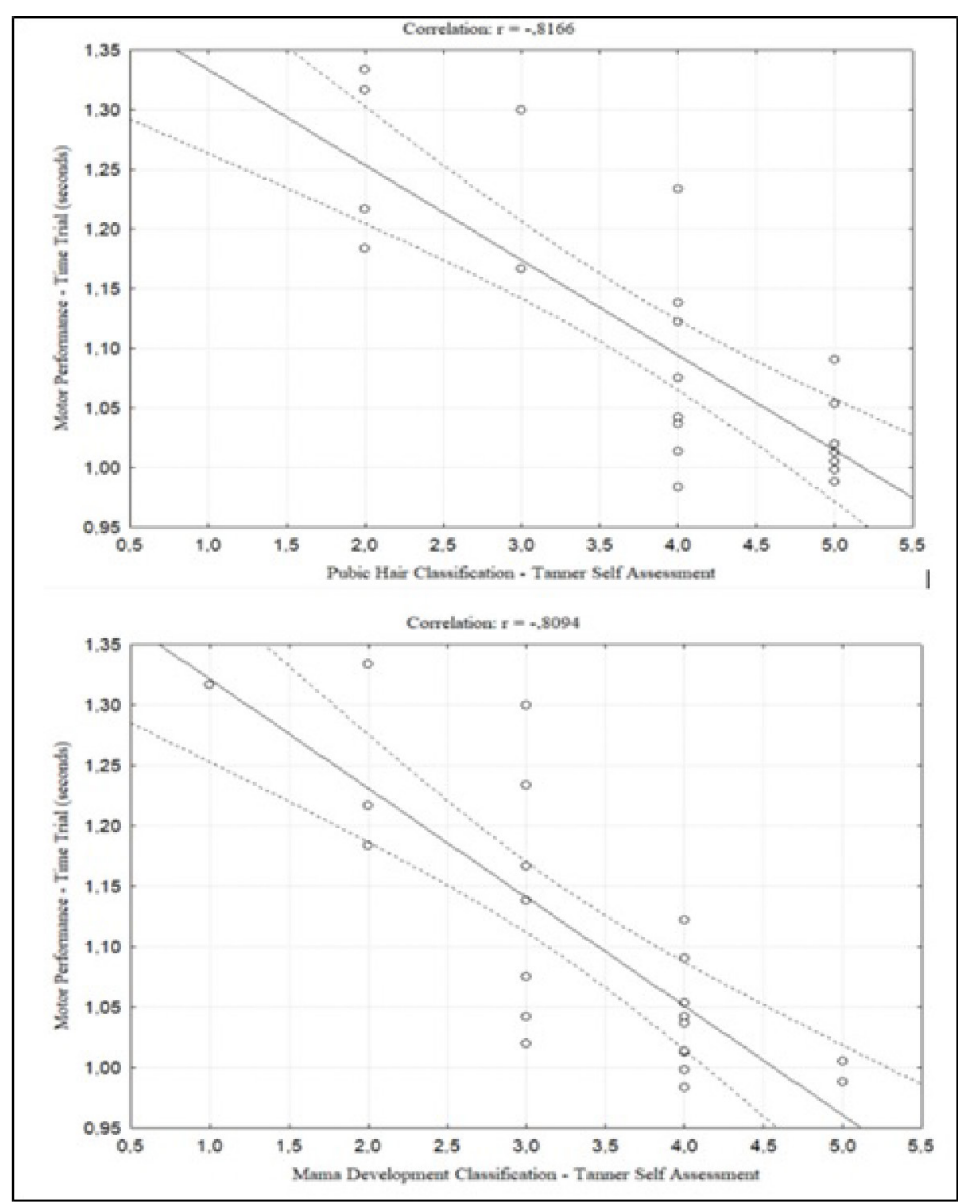

Figure 1 - Scarplott - Motor Performance x Pubic Hair classification in Tanner Self-Assessment, and Motor Performance x Mama Development Classification in Tanner Self-Assessment. 


\section{Discussion}

The main of this study was to investigate whether the difference in the maturational and anthropometric status of competitive swimmers teenage pre- and post-menarche induces influence on the motor performance of a $100-\mathrm{m}$ freestyle swimming test. The results suggested that the post-menarche swimmers had better motor performance than pre-menarche participants. Interestingly, the post-menarche group demonstrated a lower sum of skinfold thickness measures (triceps + abdomen + thigh) than the pre-menarche group, contrary to what is expected in this post-menarche population ${ }^{11,15}$.

In swimming training traditional methodology, during the development of the practitioners and their motor expertise, the volume and intensity of the activities are gradually increased. This increment induces higher energy expenditure for performing the training ${ }^{12,16}$, which may explain the lower skinfold thickness of the post-menarche if compared to the pre-menarche group.

In the exploratory analysis, we identified that the anthropometric characteristics did not demonstrate relation with the motor performance for pre-menarche swimmers teenagers. Maybe the aspects regarding physical and fitness capability are less critical to the motor performance in the initial years of swimming practice, given that the most improvement in motor performance may be acquired from the progress of the movement pattern of the swimming technique instead of physical conditioning ${ }^{17-19}$.

This perspective corroborates with the study of Lätt et al. ${ }^{20}$, which follows 25 young female swimmers for 2 years. The authors identified that the improvement of swimming performance during the growth and biological maturation was mainly related to the improvement in the biomechanical factors followed by the bioenergetic and physical factors. This finding may explain why anthropometric characteristics did not predict the motor performance in the pre-menarche group.

Also, our results revealed that post-menarche teenage swimmers demonstrated a relation of the age and anthropometric characteristics with the motor performance in the $100-\mathrm{m}$ freestyle swimming test. In this sense, a lower age and body weight and a higher height predicted better motor performance for these participants. Interestingly, body fat composition was not a determinant of motor performance. These results suggest that the critical aspect of the maturational status on the motor performance of teenage swimmers is related to somatic grown of the body segments.

Given that the somatic grown is accelerated close to the menarche occurrence ${ }^{21}$, this condition induces problems in the body schema representation ${ }^{22}$. In this way, the teenage swimmer needs to reorganize her movement pattern according to the new body schema developed in this maturational phase, and during this period of adaptation, the motor performance may be harmed ${ }^{23}$.

In this way, our findings suggested that the maturational status level pre-menarche occurrence may not influence motor performance in teenage swimmers. Because, for these participants, the morphological conditions were not related to motor performance. We suppose that for pre-menarche swimmers, the biomechanical factors related to the swimming technique are the critical element of the motor performance instead of the maturational level. On the other hand, we identified that the somatic growth (weight and height) post-menarche predicts the motor performance in the $100-\mathrm{m}$ freestyle swimming test. As well, the time of menarche was not related to motor performance.

Then, menarche occurrence per se (and the time from its event) maybe is not enough sensitive to detect the maturational aspects which are related to the motor performance in teenage swimmers. It is necessary complementary maturation inferences (such as Tanner stages) to have a better comprehension of the influence of maturational and development status of these young athletes on the swimming performance.

Our data support the need to use complementary strategies to assess the maturation besides the menarche. In our analysis, we identified a strong negative correlation between the time trial in the 100-m freestyle swimming test and the Tanner self-assessment test, for both pubic hair and mama development. This finding reinforces the argument to infer maturation status in swimming athletes using other assessment instruments, as the Tanner self-assessment test, which is an available, replicable, cost-free, and effective maturational assessment tool.

As limitations of our study, we can mention 1 - the restricted number of participants. Our sample was limited because only adolescent swimmers at the competition level (Sao Paulo Aquatic Federation) were included. This limited number of participants may impact the power of the analyses run in this study. 2 - our research did not assess the impact of motor expertise in maturational condition and motor performance. Given that the swimming technique impact motor performance as far as bioenergetic and physical factors, in the inference about the relationship between maturational status and swimming performance, maybe the motor expertise can be a confusion variable. Further investigations may develop longitudinal studies with a higher number of participants and controlling the time of swimming practice throughout adolescence.

\section{Conclusion}

Post-menarche teenage swimmers demonstrated better motor performance in the 100-m freestyle swimming test than pre-menarche swimmers. For pre-menarche swimmers, the personal and anthropometric characteristics did not predict the motor performance; instead, in post-menarche swimmers, the age, height, and weight are associated with a decrease in the motor performance in a $100-\mathrm{m}$ freestyle swimming test.

\section{References}

1. Malina R, Bouchard C, Bar-Or O. Growth, Maturation, and Physical Activity. 2nd ed. Champaign Illinois: Human Kinetic; 2004.

2. Erlandson MC, Sherar LB, Mirwald RL, Maffulli N, BaxterJones ADG. Growth and Maturation of Adolescent Female Gymnasts, Swimmers, and Tennis Players. Med Sci Sport Exerc. 2008;40(1):34-42. doi:10.1249/mss.0b013e3181596678 
3. Klug DP, Fonseca PHS da. Análise da maturação feminina: um enfoque na idade de ocorrência da menarca. Rev educ fis. 2006;17(2):139-147.

4. Kasa-Vubu JZ, Ye W, Borer KT, Rosenthal A, Meckmongkol T. Twenty-Four Hour Growth Hormone and Leptin Secretion in Active Postpubertal Adolescent Girls: Impact of Fitness, Fatness, and Age at Menarche. J Clin Endocrinol Metab. 2006;91(10):3935-3940. doi:10.1210/jc.2005-2841

5. Junqueira Do Lago M, Faerstein E, De Souza Lopes C, Werneck GL. Family socio-economic background modified secular trends in age at menarche: evidence from the Pró-Saú Study (Rio de Janeiro, Brazil). Ann Hum Biol. 2003;30(3):347-352. doi:10.1080/0301446031000091783

6. Schtscherbyna A, Barreto T, Oliveira FP de, Luiz RR, Soares E de A, Ribeiro BG. A idade do início do treinamento, e não a composição corporal, está associada com disfunções menstruais em nadadoras adolescentes competitivas. Rev Bras Med do Esporte. 2012. doi:10.1590/s1517-86922012000300004

7. Claessens AL, Bourgois J, Beunen G, Philippaerts G, Thomis $\mathrm{M}$, Lefevre J, et al. Age at menarche in relation to anthropometric characteristics, competition level and boat category in elite junior rowers. Ann Hum Biol. 2003;30(2):148-159. doi:10.1080/0301446021000034633

8. Frisch RE. Delayed Menarche and Amenorrhea of College Athletes in Relation to Age of Onset of Training. JAMA J Am Med Assoc. 1981;246(14):1559. doi:10.1001/jama.1981.03320140047029

9. Little NG, Day JAP, Steinke L. Relationship of physical performance to maturation in perimenarchal girls. Am J Hum Biol. 1997;9(2):163-171. doi:10.1002/ (SICI)1520-6300(1997)9:2<163::AID-AJHB2>3.3.CO;2-5

10. Van Den Berg L, Coetzee B, Pienaar AE. The influence of biological maturation on physical and motor performance talent identification determinants of U-14 provincial girl tennis players. J Hum Mov Stud. 2006;50(4):273-290.

11. Sharma K, Talwar I, Sharma N. Age at menarche in relation to adult body size and physique. Ann Hum Biol. 1988;15(6):431434. doi:10.1080/03014468800000032

12. Lavoie JM, Montpetit RR. Applied Physiology of Swimming. Sport Med An Int J Appl Med Sci Sport Exerc. 1986. doi:10.2165/00007256-198603030-00002

13. Lohman TJ, Roache AF, Martorell R. Anthropometric Standardization Reference Manual. Med Sci Sport Exerc. 1992;24(8):952. doi:10.1249/00005768-199208000-00020

14. Tanner JM. Growth at Adolescence. 2nd ed. Oxford: Blackwell Scientific Publications; 1962.

15. Biassio LG, Matsudo SMM, Matsudo VKR. Impacto Da Menarca Nas Variáveis Antropométricas E Neuromotoras Da Aptidão
Física, Analisado Longitudinalmente. Rev bras ciênc mov. 2004;12:97-101.

16. Rocha HA, Marinho DA, Ferreira SS, Costa AM. Organização e metodologia de ensino da natação no $1^{\circ}$ ciclo do ensino básico em Portugal. Motricidade. 2014;10(2). doi:10.6063/ motricidade.10(2).2709

17. Freudenheim AM, Madureira F. Natação: Análise e ensino do nado crawl. In: Tani G, Bento JO, Petersen RDS, eds. Pedagogia Do Desporto. Guanabara. Rio de Janeiro; 2006:372-383.

18. Light R. Learner-centred pedagogy for swim coaching: a complex learning theory-informed approach. Asia-Pacific J Heal Sport Phys Educ. 2014;5(2):167-180. doi:10.1080/18377122.2014.906056

19. Light R, Wallian N. A Constructivist-Informed Approach to Teaching Swimming. Quest. 2008;60(3):387-404. doi:10.1080/ 00336297.2008.10483588

20. Lätt E, Jürimäe J, Haljaste K, Cicchella A, Purge P, Jürimäe T. Physical development and swimming performance during biological maturation in young female swimmers. Coll Antropol. 2009;33(1):117-122. http://www.ncbi.nlm.nih.gov/ pubmed/19408614.

21. Gallahue DL, Ozmun JC. Understanding Motor Development: Infants, Children, Adolescents, Adults. 7th ed. New York: McGraw-Hill Education; 2012.

22. Freitas NK. Esquema corporal, imagem visual e representação do próprio corpo: questões teórico-conceituais. Ciências e Cognição. 2008;13(3):318-324.

23. Ré AHN. Crescimento, maturação e desenvolvimento na infância e adolescência: Implicações para o esporte. Motricidade. 2011;7(3):55-67. doi:10.6063/motricidade.7(3).103

\section{Corresponding author}

Giordano Marcio Gatinho Bonuzzi

State University of Piauí - Picos Campus. Br-230, 25, Picos, Piauí, 64607-760 Brazil. Telephone: +55 (89) 3422-4389

Email: giordanomgb@gmail.com

Manuscript received on July 22, 2020

Manuscript accepted on September 16, 2020

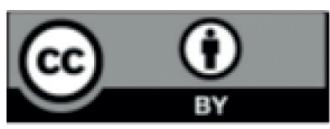

Motriz. The Journal of Physical Education. UNESP. Rio Claro, SP, Brazil - eISSN: 1980-6574 - under a license Creative Commons - Version 4.0 